\title{
Management of violence among psychiatric in-patients
}

\author{
Meena Aganwal and Mark Roberts
}

\begin{abstract}
In a retrospective study at a medium secure unlt, the incident reports where a degree of restraint was used in deciling with in-patient aggression were examined for management strategies used and their relationship to various factors. There was a decrease in the use of seclusion over the period of study, seclusion being more likely to be used when agression was aimed at staff and property, following staff-patient inferaction (demands) and younger age of perpetrators.
\end{abstract}

Violence has always been a serious problem in psychiatric hospitals (Smith \& Hucker, 1991) and, over the past two decades, the incidence among psychiatric in-patients has been increasing (James et al, 1990). Measures to control violent episodes have included physical restraint, treatment with drugs, psychotherapeutic and behavioural approaches. There has been increasing emphasis on the use of least restrictive measures. This study was undertaken to examine the possible changes in strategies chosen to manage violent incidents and to determine the factors influencing the choice.

\section{The study}

This study was undertaken over a two year period in a medium secure unit of a traditional large psychiatric hospital in north west England. It is the policy of the unit that a full report is prepared when a degree of restraint is used upon any in-patient displaying violence. The report, compiled by the nurse involved in the incident, records the date of incident, name of the patient, date of birth, legal status, description of incident, patient's behaviour prior to the incident, precipitating factors, action taken at the time, name of staff who gave assistance, injuries to patient, other patients, staff, damage to property and the medical officer's comments.

All the reports on restraint completed during 1991 and 1992 were examined: the management strategies and the relationship between factors influencing choice of management are reported below. Statistical analysis was carried out using $\chi^{2}$ test with Yates' correction.

\section{Findings}

1. Nature of management strategies: this study involved use of those reports where physical restraint was necessary. Other measures used were: seclusion, time out, drug administration and counselling (Table 1). In 1991, there were 70 incidents of violence requiring restraint and in 1992, there were 65 incidents. Seclusion was used significantly more in 1991 whereas drugs were used significantly more in 1992.

2. Factors affecting choice of management. The choice of management was examined in relation to the nature of target, the context of violence and the age of perpetrator (Table 2). The differences in the overall choice of management are significant, contributed by: increased use of seclusion when aggression was targeted at staff and property, followed staff request and in younger patients (under 40 years); and increased use of time out when aggression was aimed at fellow patients and followed inter-patient friction.

3. Number of staff involved in control of aggression (Table 3). Even though there is no significant difference over the period of study, in 1992, a small percentage $(5 \%)$ of incidents required six or more staff to control the aggressive episode.

4. Timing of staff intervention. On more than half the occasions (53\% in 1991 and $51 \%$ in 1992) staff intervened well before the actual

Table 1. Nature of management strategies

\begin{tabular}{|c|c|c|c|c|c|}
\hline & \multicolumn{2}{|c|}{$1991(n=70)$} & \multicolumn{2}{|c|}{$1992(n-65)$} & \multirow[b]{2}{*}{$\boldsymbol{P}$} \\
\hline & $n$ & (\%) & $n$ & (\%) & \\
\hline $\begin{array}{l}\text { Seclusion } \\
\text { Time out } \\
\text { Drugs } \\
\text { Counselling }\end{array}$ & $\begin{array}{r}29 \\
17 \\
2 \\
6\end{array}$ & $\begin{array}{r}(41) \\
(24) \\
(3) \\
(8)\end{array}$ & $\begin{array}{r}18 \\
21 \\
13 \\
9\end{array}$ & $\begin{array}{l}(28) \\
(32) \\
(20) \\
(14)\end{array}$ & $\begin{array}{l}<0.05 \\
\text { NS } \\
<0.0001 \\
\text { NS }\end{array}$ \\
\hline
\end{tabular}


Table 2. Factors affecting choice of management

\begin{tabular}{lcccc}
\hline Variables & $\begin{array}{l}\text { Seclusion } \\
\boldsymbol{n}\end{array}$ & $\begin{array}{l}\text { Tme out } \\
\boldsymbol{n}\end{array}$ & $\begin{array}{l}\text { Drugs } \\
\boldsymbol{n}\end{array}$ & $\begin{array}{l}\text { Counselling } \\
\boldsymbol{n}\end{array}$ \\
\hline Target & 34 & 20 & 10 & 12 \\
Staff $(n=94)$ & 6 & 16 & 2 & 2 \\
Fellow patient $(n=28)$ & 7 & 2 & 3 & 1 \\
Property $(n=13)$ & & & & \\
Context & 11 & 2 & 5 & 6 \\
Staff request $(n=24)$ & 4 & 14 & 2 & - \\
Interpatient friction $(n=26)$ & 10 & 7 & 2 & 3 \\
Psychosis $(n=22)$ & 22 & 15 & 6 & 6 \\
Unprovoked $(n=63)$ & & & & \\
Age of perpetrator & 20 & 6 & 2 & 11 \\
$20-29$ years $(n=64)$ & 21 & 20 & 6 & 3 \\
$30-39$ years $(n=46)$ & - & - & - & - \\
$40-49$ years $(n=0)$ & 6 & 12 & 7 & 1 \\
50 years \& over $(n=25)$ & & & & \\
\hline
\end{tabular}

physical assault, often following abusive and threatening behaviour by the patient.

\section{Comment}

Most psychiatric units have experienced a shift towards least restrictive measures in the management of violent behaviour even though an increase in violence has been reported (Noble \& Rodger, 1989; James et al, 1990). On the other hand, Walker \& Seifert (1994) reported the opening of a psychiatric intensive care unit in City and Hackney Health District in 1990 due to nurses' difficulties in dealing with increased violence on an open ward. In our study a shift towards use of less restrictive measures was also noted. There was a significant decrease in the use of seclusion and a corresponding increase in the use of time out, counselling and emergency drug administration. Drinkwater (1982) reported use of seclusion in 39\% of incidents, very similar to our findings in 1991. Similarly, the use of emergency drugs in $20 \%$ of incidents is very similar to that reported by Larkin et al (1988-19\%); Tobin et al (1991-24\%) and

Table 3. Number of staff involved in control of aggression

\begin{tabular}{llll}
\hline $\begin{array}{l}\text { Number } \\
\text { of staff }\end{array}$ & $\begin{array}{l}1991(n=70) \\
n(\%)\end{array}$ & $\begin{array}{l}1992(n=65) \\
n(\%)\end{array}$ & Significance \\
\hline 2 or less & $20(28)$ & $18(27)$ & NS \\
3 to 5 & $50(72)$ & $45(68)$ & NS \\
6 or more & - & $3(5)$ & NS \\
\hline
\end{tabular}

Drinkwater (1982-20\%). However, in our study counselling was used much less $(14 \%$ in 1992) as compared to Tobin et al (1991$47 \%$ ) and Drinkwater (1982-30\%).

Tobin et al (1991) also drew attention to the relationship between the use of various measures and the nature of target and the context of violence. There are similarities in our study where seclusion was used more often if the aggression was aimed at staff members or property but less often aimed at other patients. Also aggression following a staff request or due to psychosis was more likely to be dealt with by seclusion than aggression following interpatient friction.

The number of staff involved in dealing with a violent episode also determines the management strategy. Noble \& Rodger (1989) reported that $60 \%$ of incidents were dealt with by two or fewer staff, $37 \%$ of incidents by three to five and $3 \%$ of incidents by six or more staff. The numbers of staff involved is determined by the numbers immediately available on the ward, though help from outside the ward is often summoned. In our study, in 1992, two or less staff were involved in $27 \%$ of incidents, three to five staff were involved in $68 \%$ of incidents and six or more staff involved in 5\% of incidents, which reflected a high level of staffing. However, there may be other reasons, e.g. possible increase in seriousness of violent behaviour due to more patients detained under Criminal sections of the Mental Health Act admitted in 1992. Whatever the reason, it clearly leads to effective and better management of situations. 
Another important factor is the speed with which the staff act in the event of an aggressive episode. Noble \& Rodger (1989) reported that some assaults rated I or II (Fottrell, 1980) might have been more serious but for the intervention of other staff. In our study, on more than half the occasions staff acted well before the actual physical assault, often following abusive and threatening behaviour, thus preventing the situation from escalation.

Studies have reported that younger patients are more likely to be violent (Tardiff \& Sweillam, 1982; James et al, 1990) but none has attempted to establish a relationship between age of perpetrator and choice of management. In our study seclusion was used significantly more often for perpetrators under the age of 40 years than those of older age groups. Management of violence by inpatients is fraught with difficulties because of unpredictability. Risk factors include history of drug abuse and past criminal record (Walker \& Seifert, 1994), history of violence (Yesavage, 1984), schizophrenia, particularly those with disordered thinking (Tardiff \& Sweillam, 1982), younger age group and high arousal prior to assault (Alken, 1984). When it comes to dealing with individual episodes of violence, observational, verbal and behavioural skills in addition to physical control strategies (Coldwell \& Naismith, 1989) are of utmost importance.

\section{Acknowledgement}

The authors wish to acknowledge the help of Mrs Anne Grunshaw in the preparation of the manuscript.

\section{References}

AIKEN, G. J. M. (1984) Assaults on staff in a locked ward: prediction and consequences. Medicine, Science and Law, 24, 199-207.

COLDWELL, J. B. \& NAISMTrH, L. J. (1989) Violent incidents on special care wards in a Special Hospital. Medicine Science and Law, 29, 116-123.

DRINKWATER, J. (1982) Violent in psychiatric hospitals. In Developments in the Study of Criminal Behaviour: Vol 2 Violence (ed. P. Feldman). Chichester: John Wiley \& Sons.

FOTTREL. E. (1980) A study of violent behaviour among inpatients in psychiatric hospitals. British Journal of Psychiatry. 136. 216-221.

JAMES. D. V.. Fineberg, N. A.. SHAh, A. K., et al (1990). An increase in violence on an acute psychiatric ward - a study of associated factors. British Journal of Psychiatry. 166, 846-852.

LARKIN, E., MURTAGH, S. \& JONES, S. (1988) A preliminary study of violent incidents in a special hospital (Rampton). British Joumal of Psychiatry. 163, 226-231.

NoBle. P., \& RODGER, S. (1989) Violence by psychlatric inpatients. British Journal of Psychiatry. 163, 384-390.

SMrTH. J. E. \& HuCKER, S. J. (1991) Violence. Current Opinion in Psychiatry. 4, 841-845.

TARDIFF, K. \& SWEILAAM, A. (1982) Assaultive behaviour among chronic psychiatric inpatients. American Joumal of Psychiatry. 139, 212-215.

TOBIN. M.. LM. L. \& FALOWSK. W. (1991) How do we manage violent behaviour. British Joumal of Clinical and Social Psychiatry. 8. 19-23.

WALKER, Z. \& SEIFERT. R. (1994) Violent incidents in a Psychiatric Intenstve Care Unit. British Journal of Psychiatry. 164, 826-828.

YESAVAGE. J. A. (1984) Correlates of dangerous behaviour by schizophrenics in hospitals. Joumal of Psychiatric Research, 18, 225-231.

*Meena Agarwal, Senior Registrar in Child psychiatry: and Mark Roberts, Senior Registrar in Forensic Psychiatry, Ashworth Hospital, Maghull, Liverpool L31 1HW

*Correspondence: 46 Larkhill Cottages, Old Langho, Blackburn BB6 8AR 